\title{
Oxidative Stress is Closely Associated with Increased Arterial Stiffness, Especially in Aged Male Smokers without Previous Cardiovascular Events: A Cross-Sectional Study
}

\author{
Tomonori Sugiura ${ }^{1}$, Yasuaki Dohi ${ }^{2}$, Hiroyuki Takase ${ }^{3}$, Sumiyo Yamashita ${ }^{1}$, Satoshi Fujii ${ }^{4}$ and \\ Nobuyuki Ohte ${ }^{1}$ \\ ${ }^{1}$ Department of Cardio-Renal Medicine and Hypertension, Nagoya City University Graduate School of Medical Sciences, Nagoya, \\ Japan \\ ${ }^{2}$ Department of Internal Medicine, Faculty of Rehabilitation, Nagoya Gakuin University, Nagoya, Japan \\ ${ }^{3}$ Department of Internal Medicine, Enshu Hospital \\ ${ }^{4}$ Department of Laboratory Medicine, Asahikawa Medical University, Asahikawa, Japan
}

\begin{abstract}
Aim: Cigarette smoking is one of the major risk factors for cardiovascular diseases and induces deleterious vascular damage. Oxidative stress is involved in vascular inflammation, the process of atherosclerosis. The purpose of the present study was to investigate whether the effects of oxidative stress on the arterial wall differ between smokers and non-smokers.

Methods: Male smokers and non-smokers without physical deconditioning who visited Enshu hospital for an annual physical check-up were enrolled in the study. To assess oxidative stress, serum levels of derivative reactive oxygen metabolites $(\mathrm{d}-\mathrm{ROM})$ were measured. The radial augmentation index (RAI) was measured using an automated device and was used as an index for arterial stiffness.

Results: Univariate and multivariate linear regression analysis showed that RAI was independently associated with d-ROM levels only in smokers. Moreover, RAI was significantly higher in smokers than in non-smokers. Logistic regression analysis with the endpoint of a higher RAI than the mean revealed that older age ( $>65$ years), hypertension, and smoking were independently associated with higher RAI. Similarly, logistic regression analysis with the endpoint of higher d-ROM levels than the mean showed that older age and smoking were independently associated with higher d-ROM levels.

Conclusions: Increased RAI is significantly associated with smoking and, in smokers, with increased d-ROM levels. These results suggest that the effects of oxidative stress on arterial properties differ between smokers and non-smokers and that oxidative stress is closely associated with arterial stiffness, especially in smokers.
\end{abstract}

Key words: Cigarette smoking, Oxidative stress, Arterial stiffness, Radial augmentation index

\section{Introduction}

The vascular endothelium is essential for maintaining homeostasis in healthy vascular systems, and injury to the vascular endothelium is an early process of atherosclerosis, a chronic inflammatory disease of the vascular wall ${ }^{1)}$. Cigarette smoking provokes endo-

Address for correspondence: Tomonori Sugiura, Department of Cardio-Renal Medicine and Hypertension, Nagoya City University Graduate School of Medical Science, Kawasumi 1, Mizuho-cho, Mizuho-ku, Nagoya 467-8601, Japan

E-mail: tomosugi@med.nagoya-cu.ac.jp

Received: December 4, 2016

Accepted for publication: May 14, 2017 thelial damage, accelerates the progression of atherosclerosis, and increases cardiovascular risk even at low levels of smoking or with low-tar cigarettes ${ }^{2-5}$. Cigarette smoke contains various chemical substances that have not been completely identified, but most of the substances identified thus far are known to be harmful to cardiovascular systems ${ }^{5,6}$. Complications of cardiovascular risk factors, including cigarette smoking, often include increased oxidative stress and the promotion of inflammatory activation of the endothelium, leading to atherosclerosis ${ }^{7-9)}$. Oxidative stress is recognized as an initial common pathway of vascular damage, and smoking is one of the most unfavorable risk factors with regard to the production of oxidative 
Table 1. Characteristics of the study subjects

\begin{tabular}{lccc}
\hline \multicolumn{1}{c}{ Variable } & $\begin{array}{c}\text { All subjects } \\
(n=909)\end{array}$ & $\begin{array}{c}\text { Smokers } \\
(n=263)\end{array}$ & $\begin{array}{c}\text { Non-smokers } \\
(n=646)\end{array}$ \\
\hline Age (years) & $58 \pm 12$ & $54 \pm 12^{* * *}$ & $60 \pm 12$ \\
BMI (kg/m ${ }^{2}$ ) & $22.8 \pm 3.0$ & $22.8 \pm 3.0$ & $22.8 \pm 3.0$ \\
Systolic BP (mmHg) & $124 \pm 14$ & $122 \pm 13^{*}$ & $125 \pm 14$ \\
Diastolic BP (mmHg) & $75 \pm 3$ & $75 \pm 9$ & $75 \pm 9$ \\
Hemoglobin (g/dL) & $14.5 \pm 1.1$ & $14.8 \pm 1.1^{* * *}$ & $14.4 \pm 1.1$ \\
Creatinine (mg/dL) & $0.87 \pm 0.16$ & $0.83 \pm 0.13^{* * *}$ & $0.88 \pm 0.17$ \\
FPG (mg/dL) & $99 \pm 19$ & $96 \pm 17^{*}$ & $100 \pm 19$ \\
Total cholesterol (mg/dL) & $193 \pm 30$ & $189 \pm 31^{*}$ & $194 \pm 30$ \\
HDL-C (mg/dL) & $58 \pm 15$ & $54 \pm 14^{* * *}$ & $59 \pm 16$ \\
LDL-C (mg/dL) & $120 \pm 27$ & $119 \pm 29$ & $121 \pm 27$ \\
Triglycerides (mg/dL) & $109 \pm 59$ & $118 \pm 68^{* *}$ & $106 \pm 54$ \\
AST (U/L) & $20.8 \pm 4.9$ & $19.8 \pm 5.0^{* * *}$ & $21.2 \pm 4.8$ \\
ALT (U/L) & $19.8 \pm 7.4$ & $19.6 \pm 7.6$ & $19.9 \pm 7.3$ \\
Uric acid (mg/dL) & $5.9 \pm 1.1$ & $5.9 \pm 1.2$ & $5.8 \pm 1.1$ \\
eGFR (mL/min per $\left.1.73 \mathrm{~m}^{2}\right)$ & $73.5 \pm 13.5$ & $78.5 \pm 12.9^{* * *}$ & $71.5 \pm 13.2$ \\
Radial augmentation index (\%) & $79.4 \pm 11.7$ & $81.6 \pm 13.1^{* *}$ & $78.6 \pm 10.9$ \\
d-ROM (Carratelli units) & $340 \pm 54$ & $342 \pm 54$ & $339 \pm 54$ \\
Smoking duration (years) & - & $27 \pm 13$ & - \\
Number of cigarettes smoked per day & - & $18.7 \pm 8.3$ & - \\
Brinkman index & $515 \pm 345$ & - \\
\hline
\end{tabular}

Data are given as the mean \pm SD. ${ }^{*} p<0.05,{ }^{* *} p<0.01,{ }^{* * *} p<0.0001$ compared with non-smokers.

$\mathrm{BMI}$, body mass index; BP, blood pressure; FPG, fasting plasma glucose; HDL-C, high-density lipoprotein cholesterol; LDL-C, low-density lipoprotein cholesterol; AST, aspartate transaminase; ALT, alanine transaminase; eGFR, estimated glomerular filtration rate; $\mathrm{d}$-ROM, derivatives of reactive oxygen metabolites.

stress in the cardiovascular system ${ }^{7-9)}$. However, quantification of oxidative stress using several laboratory methods, such as oxidized low-density lipoprotein and 8-isoprostane, occasionally leads to different conclusions ${ }^{10)}$. Therefore, for the maintenance of healthy vascular systems, it is important not only to measure oxidative stress markers, but also to assess the effects of oxidative stress on the vascular system.

Cigarette smoking increases serotonin levels in platelets ${ }^{11}$. Generally, serotonin synthesized by enterochromaffin cells in the gastrointestinal tract is incorporated into platelets and is released to the plasma upon platelet activation ${ }^{12-14)}$. Released serotonin modulates vascular tonus and thrombus formation, and it mediates the development and/or rupture of atherosclerotic plaques ${ }^{12-14)}$. We have recently reported that plasma concentrations of serotonin were associated with endothelial damage in smokers and that 8 weeks smoking cessation failed to decrease plasma serotonin concentrations ${ }^{14)}$. Thus, cigarette smoking is related to a disorder in vascular systems, and the effects last for at least a few months after smoking cessation.

In the present study, we tested the hypotheses that oxidative stress adversely affects the arterial wall, especially in smokers, and that the effects of oxidative stress on arterial stiffness are greater in smokers than in non-smokers. The aim of the present study was to investigate the effects of oxidative stress on arterial stiffness in smokers and non-smokers.

\section{Materials and Methods}

Male subjects without physical deconditioning who were either habitual smokers or not were enrolled in the present study. The study protocol was approved by the ethics committees of Nagoya City University Graduate School of Medical Sciences and Enshu Hospital. The study was performed in accordance with the principles of the Declaration of Helsinki. Written informed consent was obtained from each participant prior to the start of the study.

\section{Subjects}

Approximately half of all Japanese adults undergo a physical check-up every year in either public or private institutions. Enshu Hospital is one of the institutions that performs physical check-ups, which are medical examinations performed from the viewpoint 
Table 2. Results of univariate regression analysis of factors possibly associated with the radial augmentation index in all subjects, smokers, and non-smokers

\begin{tabular}{|c|c|c|c|c|c|c|}
\hline \multirow{2}{*}{ Variable } & \multicolumn{2}{|c|}{$\begin{array}{l}\text { All subjects } \\
\quad(n=909)\end{array}$} & \multicolumn{2}{|c|}{$\begin{array}{l}\text { Smokers } \\
(n=263)\end{array}$} & \multicolumn{2}{|c|}{$\begin{array}{l}\text { Non-smokers } \\
\quad(n=646)\end{array}$} \\
\hline & Coefficient (r) & $p$-value & Coefficient & $p$-value & Coefficient $(\mathrm{r})$ & $p$-value \\
\hline Age (years) & 0.34 & $<0.0001$ & 0.38 & $<0.0001$ & 0.37 & $<0.0001$ \\
\hline BMI $\left(\mathrm{kg} / \mathrm{m}^{2}\right)$ & -0.11 & $<0.01$ & -0.11 & 0.098 & -0.11 & $<0.01$ \\
\hline Systolic BP (mmHg) & 0.14 & $<0.001$ & 0.15 & $<0.05$ & 0.16 & $<0.001$ \\
\hline Diastolic BP (mmHg) & 0.09 & $<0.01$ & 0.09 & 0.17 & 0.10 & $<0.05$ \\
\hline Hemoglobin $(\mathrm{g} / \mathrm{dL})$ & -0.076 & $<0.05$ & -0.11 & 0.09 & -0.09 & $<0.05$ \\
\hline Creatinine (mg/dL) & -0.052 & 0.14 & -0.11 & 0.09 & -0.002 & 0.96 \\
\hline FPG $(\mathrm{mg} / \mathrm{dL})$ & -0.061 & 0.09 & -0.14 & $<0.05$ & -0.012 & 0.77 \\
\hline Total cholesterol (mg/dL) & -0.063 & 0.08 & -0.049 & 0.46 & -0.056 & 0.18 \\
\hline HDL-C (mg/dL) & -0.042 & 0.24 & 0.04 & 0.55 & 0.05 & 0.22 \\
\hline LDL-C (mg/dL) & -0.086 & $<0.05$ & -0.12 & 0.07 & -0.060 & 0.16 \\
\hline Triglycerides $(\mathrm{mg} / \mathrm{dL})$ & 0.082 & $<0.05$ & 0.079 & 0.24 & 0.066 & 0.12 \\
\hline AST (U/L) & 0.064 & 0.07 & 0.048 & 0.47 & 0.096 & $<0.05$ \\
\hline ALT (U/L) & -0.072 & 0.06 & -0.087 & 0.19 & -0.070 & 0.096 \\
\hline Uric acid (mg/dl) & 0.011 & 0.75 & -0.050 & 0.46 & 0.036 & 0.40 \\
\hline eGFR $\left(\mathrm{mL} / \mathrm{min}\right.$ per $\left.1.73 \mathrm{~m}^{2}\right)$ & -0.050 & 0.16 & -0.040 & 0.55 & -0.098 & $<0.05$ \\
\hline d-ROM (Carratelli units) & 0.077 & $<0.05$ & 0.25 & $<0.001$ & -0.006 & 0.89 \\
\hline Smoking duration (years) & - & - & 0.30 & $<0.0001$ & - & - \\
\hline Number of cigarettes smoked per day & - & - & 0.033 & 0.47 & - & - \\
\hline Brinkman index & - & - & 0.22 & $<0.0001$ & - & - \\
\hline
\end{tabular}

BMI, body mass index; BP, blood pressure; FPG, fasting plasma glucose; HDL-C, high-density lipoprotein cholesterol; LDL-C, low-density lipoprotein cholesterol; AST, aspartate transaminase; ALT, alanine transaminase; eGFR, estimated glomerular filtration rate; d-ROM, derivatives of reactive oxygen metabolites.

of preventive medicine regardless of whether individuals are exhibiting subjective symptoms. Of those undergoing physical check-ups at Enshu Hospital between 2015 and $2016(n=1800), 1175$ male subjects were screened to determine their eligibility to be included in the study. Subjects who had a past smoking habit but had stopped smoking before the screening for the present study $(n=160)$ were excluded from the study. Similarly, subjects taking any medications or those with renal insufficiency (creatinine $\geq 1.5 \mathrm{mg} / \mathrm{dL}$ ), malignant neoplasm, active inflammatory disease, a history of obvious hepatic disease, or a history of cardiovascular events (stroke and myocardial infarction) were also excluded from the study $(n=106)$. Thus, 909 male subjects were included in the present study. Subjects who never smoked were defined as non-smokers, whereas those who had a smoking habit at the time of the current examination were defined as smokers. Smokers were instructed not to smoke on the day of the physical check-up. Blood samples were taken early in the morning after an overnight fast. Blood pressure (BP) was measured using a standard mercury sphygmomanometer with subjects in a seated position. Three consecutive BP measurements were taken at 2-min inter- vals, and the mean of the second and third measurements was recorded as the BP. Subjects with systolic $\mathrm{BP} \geq 140 \mathrm{mmHg}$ and diastolic $\mathrm{BP} \geq 90 \mathrm{mmHg}$ were defined as having hypertension ${ }^{15)}$. Subjects with highdensity lipoprotein cholesterol (HDL-C) $<40 \mathrm{mg} / \mathrm{dL}$, low-density lipoprotein cholesterol (LDL-C) $\geq 140 \mathrm{mg} /$ $\mathrm{dL}$, or triglycerides $\geq 150 \mathrm{mg} / \mathrm{dL}$ were defined as having dyslipidemia ${ }^{16}$. Subjects with a fasting plasma glucose (FPG) level $\geq 126 \mathrm{mg} / \mathrm{dL}$ were defined as having diabetes mellitus, whereas subjects with FPG $\geq 111$ and $<126 \mathrm{mg} / \mathrm{dL}$ were defined as having impaired glucose tolerance $^{17)}$.

\section{Biochemical Analysis}

Biochemical tests, including serum total cholesterol, LDL-C, HDL-C, and triglyceride levels, were performed using standard laboratory assays. In terms of the various oxidative markers, a simple method of detecting hydroperoxide levels by measuring derivative reactive oxygen metabolites (d-ROM) has been reported to be useful for evaluating oxidative stress ${ }^{7)}$. Therefore, serum concentrations of $\mathrm{d}$-ROM were measured in the present study to assess oxidative stress. Measurements of d-ROM levels were made as described previously ${ }^{7)}$. 
$\mathbf{A}$

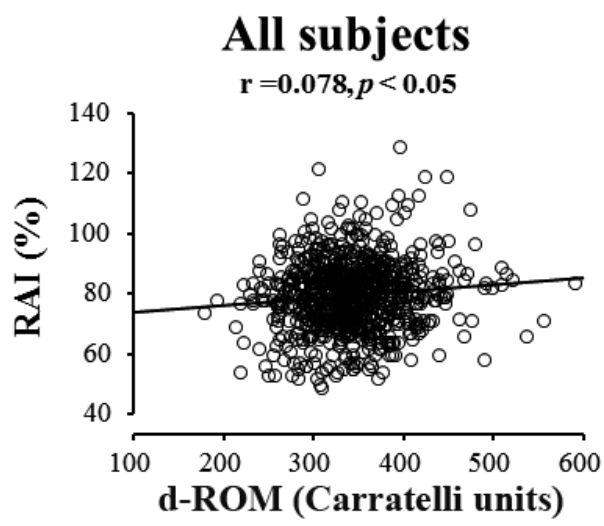

B

\section{Smokers}

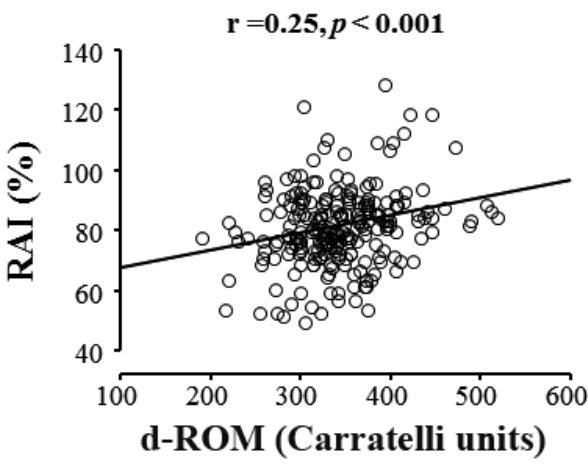

C

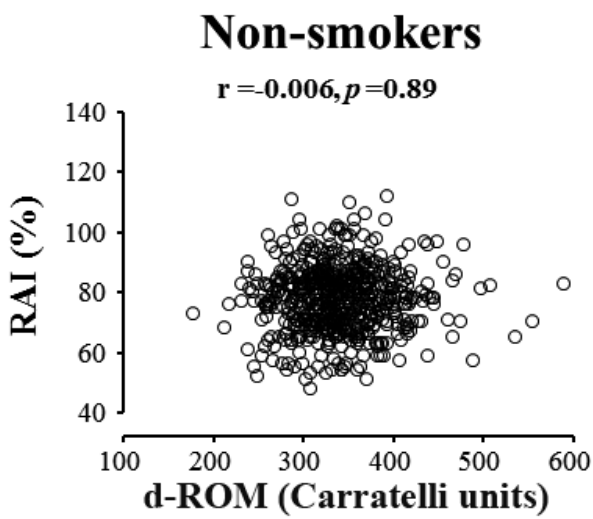

Fig. 1. Association between the levels of derivatives of reactive oxygen metabolites (d-ROM) and the radial augmentation index (RAI).

Relationships between d-ROM levels and RAI in (A) all subjects, (B) smokers, and (C) non-smokers. There was a significant correlation between d-ROM levels and RAI across all subjects and in smokers, but not in non-smokers.

Briefly, serum samples were mixed with a buffered solution, and a chromogenic substrate was then added to the mixture. Samples were immediately incubated in the analyzer for $5 \mathrm{~min}$, after which absorbance was recorded at $505 \mathrm{~nm}$, with d-ROM levels expressed in Carratelli units. The estimated glomerular filtration rate (eGFR) was calculated using a modified formula from the Modification of Diet in Renal Disease study for the Japanese population ${ }^{18)}$.

\section{Measurement of Central BP and Radial Augmenta- tion Index}

A fully automated device (HEM-9000AI) was used for the measurement of radial artery pressure waveforms and an estimation of central BP, as described previously ${ }^{19,20)}$. The radial augmentation index (RAI), which has been reported to be a marker of arterial stiffness and subclinical atherosclerosis, was calculated using the following equation:

$$
\text { RAI }(\%)=(\mathrm{P} 2 / \mathrm{PP}) \times 100 \text {, }
$$

where P2 and PP are the height of the late systolic shoulder/peak pressure and the pulse pressure of the radial arterial pressure contour, respectively ${ }^{21,22)}$.

\section{Statistical Analysis}

Data were analyzed using IBM SPSS Statistics 19 (IBM Corp., Chicago, IL, USA) and are expressed as the mean $\pm S D$. Histograms of $d-R O M$ and RAI showed an approximately normal distribution for both parameters. Dichotomous variables were assigned values of 0 and 1. Comparisons of continuous variables were performed using paired or unpaired $t$-tests, as appropriate. Univariate and multivariate linear regression analyses associated with RAI were performed. Two-tailed $p<0.05$ was considered statistically significant.

\section{Results}

The characteristics of all of the study subjects, as well as for smokers and non-smokers separately, are 
Table 3. Results of multivariate regression analysis ${ }^{\mathrm{a}}$ for factors possibly associated with the radial augmentation index in all subjects, smokers, and non-smokers

\begin{tabular}{|c|c|c|c|}
\hline Variable & $\begin{array}{c}\text { Standardized } \\
\text { coefficient }\end{array}$ & $\begin{array}{l}\text { Standard } \\
\text { error }\end{array}$ & $p$-value \\
\hline \multicolumn{4}{|l|}{ All subjects } \\
\hline \multicolumn{4}{|l|}{ Non-interaction model } \\
\hline Age (years) & 0.40 & 0.039 & $<0.0001$ \\
\hline BMI $\left(\mathrm{kg} / \mathrm{m}^{2}\right)$ & -0.12 & 0.15 & $<0.001$ \\
\hline Systolic BP (mmHg) & 0.016 & 0.040 & 0.74 \\
\hline Diastolic BP (mmHg) & 0.12 & 0.058 & $<0.01$ \\
\hline Hemoglobin $(\mathrm{g} / \mathrm{dL})$ & 0.023 & 0.39 & 0.52 \\
\hline FPG (mg/dL) & -0.12 & 0.022 & $<0.001$ \\
\hline HDL-C (mg/dL) & -0.020 & 0.028 & 0.59 \\
\hline LDL-C (mg/dL) & -0.060 & 0.014 & 0.07 \\
\hline Triglycerides (mg/dL) & 0.11 & 0.007 & $<0.01$ \\
\hline eGFR $\left(\mathrm{mL} / \mathrm{min}\right.$ per $\left.1.73 \mathrm{~m}^{2}\right)$ & 0.082 & 0.032 & $<0.05$ \\
\hline d-ROM (Carratelli units) & 0.023 & 0.007 & 0.48 \\
\hline Cigarette smoking & 0.16 & 0.89 & $<0.0001$ \\
\hline \multicolumn{4}{|l|}{ Interaction model } \\
\hline Product term of smoking and d-ROM & 0.68 & 0.015 & $<0.001$ \\
\hline Age (years) & 0.41 & 0.040 & $<0.0001$ \\
\hline BMI $\left(\mathrm{kg} / \mathrm{m}^{2}\right)$ & -0.12 & 0.15 & $<0.001$ \\
\hline Systolic BP (mmHg) & 0.020 & 0.040 & 0.67 \\
\hline Diastolic BP (mmHg) & 0.12 & 0.058 & $<0.01$ \\
\hline Hemoglobin $(\mathrm{g} / \mathrm{dL})$ & 0.025 & 0.39 & 0.61 \\
\hline $\mathrm{FPG}(\mathrm{mg} / \mathrm{dL})$ & -0.11 & 0.022 & $<0.001$ \\
\hline HDL-C (mg/dL) & -0.019 & 0.028 & 0.61 \\
\hline LDL-C (mg/dL) & -0.055 & 0.014 & 0.10 \\
\hline Triglycerides $(\mathrm{mg} / \mathrm{dL})$ & 0.11 & 0.007 & $<0.01$ \\
\hline $\operatorname{eGFR}\left(\mathrm{mL} / \mathrm{min}\right.$ per $\left.1.73 \mathrm{~m}^{2}\right)$ & 0.082 & 0.032 & $<0.05$ \\
\hline d-ROM (Carratelli units) & -0.057 & 0.008 & 0.14 \\
\hline Cigarette smoking & -0.51 & 5.2 & $<0.05$ \\
\hline \multicolumn{4}{|l|}{ Smokers } \\
\hline Age (years) & 0.37 & 0.089 & $<0.0001$ \\
\hline BMI $\left(\mathrm{kg} / \mathrm{m}^{2}\right)$ & -0.044 & 0.31 & 0.55 \\
\hline Systolic BP (mmHg) & 0.05 & 0.092 & 0.95 \\
\hline Diastolic BP (mmHg) & 0.12 & 0.12 & 0.15 \\
\hline Hemoglobin $(\mathrm{g} / \mathrm{dL})$ & 0.050 & 0.85 & 0.48 \\
\hline FPG $(\mathrm{mg} / \mathrm{dL})$ & -0.17 & 0.045 & $<0.01$ \\
\hline HDL-C (mg/dL) & 0.044 & 0.069 & 0.59 \\
\hline LDL-C (mg/dL) & -0.055 & 0.029 & 0.39 \\
\hline Triglycerides $(\mathrm{mg} / \mathrm{dL})$ & 0.12 & 0.13 & 0.09 \\
\hline eGFR $\left(\mathrm{mL} / \mathrm{min}\right.$ per $\left.1.73 \mathrm{~m}^{2}\right)$ & 0.11 & 0.069 & 0.11 \\
\hline d-ROM (Carratelli units) & 0.17 & 0.015 & $<0.01$ \\
\hline \multicolumn{4}{|l|}{ Non-smokers } \\
\hline Age (years) & 0.41 & 0.044 & $<0.0001$ \\
\hline BMI $\left(\mathrm{kg} / \mathrm{m}^{2}\right)$ & -0.16 & 0.17 & $<0001$ \\
\hline Systolic BP (mmHg) & 0.016 & 0.044 & 0.77 \\
\hline Diastolic BP (mmHg) & 0.12 & 0.065 & $<0.05$ \\
\hline Hemoglobin $(\mathrm{g} / \mathrm{dL})$ & 0.031 & 0.45 & 0.47 \\
\hline FPG $(\mathrm{mg} / \mathrm{dL})$ & -0.088 & 0.025 & $<0.05$ \\
\hline
\end{tabular}


(Cont Table 3)

\begin{tabular}{|c|c|c|c|}
\hline Variable & $\begin{array}{c}\text { Standardized } \\
\text { coefficient }\end{array}$ & $\begin{array}{l}\text { Standard } \\
\text { error }\end{array}$ & $p$-value \\
\hline \multicolumn{4}{|l|}{ Non-smokers } \\
\hline HDL-C (mg/dL) & -0.043 & 0.032 & 0.33 \\
\hline LDL-C (mg/dL) & -0.064 & 0.017 & 0.12 \\
\hline Triglycerides (mg/dL) & 0.11 & 0.009 & $<0.05$ \\
\hline eGFR $\left(\mathrm{mL} / \mathrm{min}\right.$ per $\left.1.73 \mathrm{~m}^{2}\right)$ & 0.076 & 0.038 & 0.08 \\
\hline d-ROM (Carratelli units) & -0.060 & 0.008 & 0.13 \\
\hline
\end{tabular}

given in Table 1. Of the 909 subjects enrolled in the study, 646 were non-smokers and 263 were smokers. Across all 909 subjects, 310 (34.1\%) had hypertension, 430 (41.3\%) had dyslipidemia, 92 (10.1\%) had diabetes mellitus, and 46 (5.1\%) had impaired glucose tolerance.

Univariate linear regression analysis revealed a significant correlation between RAI and d-ROM when the analysis was performed in the study cohort as a whole. When subjects were divided into two groups based on smoking status, similar results were obtained in smokers, but not in non-smokers, whereas age and systolic BP were significantly correlated with RAI in both non-smokers and smokers (Table 2; Fig. 1). Although the correlations between RAI and $\mathrm{d}$-ROM were statistically significant, the correlation coefficient was not high (Fig. 1A and 1B; Tables 2, 3, $\mathbf{3 a}$, and $\mathbf{3 b}$ ). Smoking duration and smoking intensity, as assessed by the Brinkman index, were significantly correlated with RAI, but there was no correlation between the number of cigarettes smoked per day and RAI (Table 2). d-ROM levels were correlated with smoking duration $(r=0.16, P<0.001)$ and the Brinkman index $(r=0.094, P<0.05)$, but not with the number of cigarettes smoked per day. Multivariate linear regression analysis revealed that RAI was independently associated with smoking in the study cohort as a whole (Table 3). Moreover, RAI was significantly higher in smokers, the elderly (i.e., those aged $>65$ years), and subjects with hypertension than in nonsmokers, those aged $\leq 65$ years, and those without hypertension, respectively (Fig. 2). A significant association between d-ROM and RAI was revealed in smokers, but not non-smokers, even after the adjustment for smoking intensity (Table 3, Table 3a, and Table $3 \mathbf{b}$ ). In contrast, body mass index (BMI), diastolic BP, and triglycerides, but not d-ROM, showed significant associations with RAI in non-smokers. Sig- nificant interaction of smoking in the association of $\mathrm{d}-\mathrm{ROM}$ and RAI was indicated (Tables 3, 3a, and 3b).

To evaluate the effects of cardiovascular risk factors, including cigarette smoking, on RAI, logistic regression analysis was conducted using categorical data with the endpoint of higher RAI than the mean. The results indicated that increased age, hypertension, and cigarette smoking were independently associated with higher RAI (Table 4). Similarly, logistic regression analysis, with the endpoint of $\mathrm{d}$-ROM levels higher than the mean, revealed that cigarette smoking was independently associated with higher d-ROM levels after an adjustment for increased age, hypertension, dyslipidemia, diabetes mellitus, and obesity (odds ratio $1.41 ; 95 \%$ confidence interval $1.05-1.90 ; P<$ $0.05)$.

\section{Discussion}

The main findings of the present study are that: (i) RAI was independently associated with d-ROM levels only in smokers, as revealed by univariate and multivariate linear regression analyses; (ii) RAI was significantly higher in smokers than in non-smokers; (iii) older age (i.e., > $>5$ years), hypertension, and smoking were independently associated with higher RAI; and (iv) older age (i.e., $>65$ years) and smoking were independently associated with higher d-ROM levels. These results indicate that oxidative stress is strongly associated with increased arterial stiffness in smokers.

Previously, we reported that oxidative stress, as assessed by d-ROM levels, was significantly associated with cardiovascular risk parameters in the general population $^{7)}$. In that study, $\mathrm{d}$-ROM levels were associated with endothelial dysfunction and markers of vascular inflammation ${ }^{7}$. In the present study, we evaluated serum d-ROM concentrations and RAI, a parameter 
Table 3a. Results of multivariate regression analysis ${ }^{\mathrm{a}}$ for factors possibly associated with the radial augmentation index adjusting for smoking intensity (Brinkman index) in all subjects, smokers, and non-smokers

\begin{tabular}{|c|c|c|c|}
\hline Variable & $\begin{array}{c}\text { Standardized } \\
\text { coefficient }\end{array}$ & $\begin{array}{l}\text { Standard } \\
\text { error }\end{array}$ & $p$-value \\
\hline \multicolumn{4}{|l|}{ All subjects } \\
\hline \multicolumn{4}{|l|}{ Non-interaction model } \\
\hline Age (years) & 0.38 & 0.057 & $<0.0001$ \\
\hline BMI $\left(\mathrm{kg} / \mathrm{m}^{2}\right)$ & -0.11 & 0.19 & $<0.05$ \\
\hline Systolic BP (mmHg) & -0.001 & 0.040 & 0.99 \\
\hline Diastolic BP (mmHg) & 0.15 & 0.076 & $<0.05$ \\
\hline Hemoglobin $(\mathrm{g} / \mathrm{dL})$ & 0.022 & 0.49 & 0.64 \\
\hline FPG $(\mathrm{mg} / \mathrm{dL})$ & -0.15 & 0.026 & $<0.001$ \\
\hline HDL-C (mg/dL) & -0.005 & 0.037 & 0.91 \\
\hline LDL-C (mg/dL) & -0.020 & 0.018 & 0.65 \\
\hline Triglycerides (mg/dL) & 0.093 & 0.009 & $<0.05$ \\
\hline eGFR $\left(\mathrm{mL} / \mathrm{min}\right.$ per $\left.1.73 \mathrm{~m}^{2}\right)$ & 0.12 & 0.041 & $<0.05$ \\
\hline d-ROM (Carratelli units) & 0.053 & 0.010 & 0.21 \\
\hline Cigarette smoking & 0.13 & 1.11 & $<0.01$ \\
\hline Brinkman index & 0.082 & 0.002 & 0.084 \\
\hline \multicolumn{4}{|l|}{ Interaction model } \\
\hline Product term of smoking and d-ROM & 0.87 & 0.018 & $<0.01$ \\
\hline Age (years) & 0.38 & 0.056 & $<0.0001$ \\
\hline BMI $\left(\mathrm{kg} / \mathrm{m}^{2}\right)$ & -0.099 & 0.19 & $<0.05$ \\
\hline Systolic BP (mmHg) & 0.007 & 0.051 & 0.90 \\
\hline Diastolic BP (mmHg) & 0.14 & 0.074 & $<0.05$ \\
\hline Hemoglobin $(\mathrm{g} / \mathrm{dL})$ & 0.029 & 0.48 & 0.53 \\
\hline $\mathrm{FPG}(\mathrm{mg} / \mathrm{dL})$ & -0.15 & 0.026 & $<0.001$ \\
\hline HDL-C (mg/dL) & -0.007 & 0.036 & 0.89 \\
\hline LDL-C (mg/dL) & -0.018 & 0.018 & 0.67 \\
\hline Triglycerides $(\mathrm{mg} / \mathrm{dL})$ & 0.095 & 0.009 & $<0.05$ \\
\hline eGFR $\left(\mathrm{mL} / \mathrm{min}\right.$ per $\left.1.73 \mathrm{~m}^{2}\right)$ & 0.11 & 0.041 & $<0.05$ \\
\hline d-ROM (Carratelli units) & -0.070 & 0.013 & 0.22 \\
\hline Cigarette smoking & -0.73 & 6.4 & $<0.01$ \\
\hline Brinkman index & 0.082 & 0.002 & 0.080 \\
\hline \multicolumn{4}{|l|}{ Smokers } \\
\hline Age (years) & 0.37 & 0.10 & $<0.0001$ \\
\hline BMI $\left(\mathrm{kg} / \mathrm{m}^{2}\right)$ & -0.014 & 0.31 & 0.85 \\
\hline Systolic BP (mmHg) & 0.011 & 0.091 & 0.85 \\
\hline Diastolic BP (mmHg) & 0.11 & 0.12 & 0.23 \\
\hline Hemoglobin $(\mathrm{g} / \mathrm{dL})$ & 0.079 & 0.84 & 0.27 \\
\hline FPG $(\mathrm{mg} / \mathrm{dL})$ & -0.20 & 0.045 & $<0.01$ \\
\hline HDL-C (mg/dL) & 0.049 & 0.069 & 0.50 \\
\hline LDL-C (mg/dL) & -0.052 & 0.029 & 0.42 \\
\hline Triglycerides (mg/dL) & 0.065 & 0.014 & 0.34 \\
\hline eGFR $\left(\mathrm{mL} / \mathrm{min}\right.$ per $\left.1.73 \mathrm{~m}^{2}\right)$ & 0.14 & 0.071 & $<0.05$ \\
\hline d-ROM (Carratelli units) & 0.18 & 0.015 & $<0.01$ \\
\hline Brinkman index & 0.078 & 0.003 & 0.32 \\
\hline \multicolumn{4}{|l|}{ Non-smokers } \\
\hline Age (years) & 0.41 & 0.044 & $<0.0001$ \\
\hline BMI $\left(\mathrm{kg} / \mathrm{m}^{2}\right)$ & -0.16 & 0.17 & $<0001$ \\
\hline Systolic BP (mmHg) & 0.016 & 0.044 & 0.77 \\
\hline
\end{tabular}


(Cont Table 3a)

\begin{tabular}{|c|c|c|c|}
\hline Variable & $\begin{array}{c}\text { Standardized } \\
\text { coefficient }\end{array}$ & $\begin{array}{l}\text { Standard } \\
\text { error }\end{array}$ & $p$-value \\
\hline \multicolumn{4}{|l|}{ Non-smokers } \\
\hline Diastolic BP (mmHg) & 0.12 & 0.065 & $<0.05$ \\
\hline Hemoglobin $(\mathrm{g} / \mathrm{dL})$ & 0.031 & 0.45 & 0.47 \\
\hline $\mathrm{FPG}(\mathrm{mg} / \mathrm{dL})$ & -0.088 & 0.025 & $<0.05$ \\
\hline HDL-C (mg/dL) & -0.043 & 0.032 & 0.33 \\
\hline LDL-C (mg/dL) & -0.064 & 0.017 & 0.12 \\
\hline Triglycerides (mg/dL) & 0.11 & 0.009 & $<0.05$ \\
\hline eGFR $\left(\mathrm{mL} / \mathrm{min}\right.$ per $\left.1.73 \mathrm{~m}^{2}\right)$ & 0.076 & 0.038 & 0.08 \\
\hline d-ROM (Carratelli units) & -0.060 & 0.008 & 0.13 \\
\hline
\end{tabular}

of arterial stiffness, instead of endothelial function, and we confirmed that smoking was independently associated with increased arterial stiffness and increased oxidative stress. Classically, arterial stiffness, which is characterized by decreased arterial elasticity, with the loss of elastic fiber content in the vascular smooth muscle layer, is thought to have different features than vascular endothelial dysfunction, but both conditions are known to be surrogate markers of cardiovascular events ${ }^{21-24)}$. Meanwhile, oxidative stress has been shown to induce increased arterial stiffness in animal models and is associated with decreased arterial elasticity ${ }^{25,26)}$. Although the correlation coefficient between RAI and d-ROM was not so high, a significant association between arterial stiffness and oxidative stress demonstrated in smokers in the present study may indicate that smoking-related oxidative stress provokes arterial stiffness and accelerates arteriosclerosis. Indeed, RAI was greater in smokers than in non-smokers even though d-ROM concentrations were comparable in these two groups.

Oxidative stress can be measured using several biological markers in both smokers and non-smokers. However, caution should be taken when interpreting the results because cigarette smoking increases inflammatory molecules in addition to promoting lipid and protein oxidation products, and so may not be identified correctly using one of the markers ${ }^{27}$. Although we had not evaluated oxidative stress in smokers using d-ROM levels, Kato et al. did evaluate d-ROM levels in 11 healthy male smokers and reported that smoking cessation for three months using varenicline significantly decreased d-ROM levels and ameliorated endothelial function ${ }^{28)}$. However, the sample in that study was too small, and the study lacked a compara- tive analysis with non-smokers ${ }^{28)}$. Hence, in the present study, we investigated the effects of oxidative stress on arterial stiffness in smokers and non-smokers and found that the effects of oxidative stress on arterial properties were not equivalent between these two groups. This may be the reason why a significant association between oxidative stress and arterial stiffness could not be observed when the analysis was performed in the study cohort as a whole, including smokers and non-smokers. Of note, d-ROM was significantly associated with smoking, but not with RAI, in all subjects. However, interaction of smoking in the association of $\mathrm{d}-\mathrm{ROM}$ and RAI was significant, suggesting that smoking significantly modified the association between oxidative stress and arterial stiffness. In smokers, an increase in oxidative stress may indicate a parallel increase in levels of several other constituents of cigarette smoke that may directly affect arterial function and increase arterial stiffness. Meanwhile, Patel et al. ${ }^{26)}$ reported a correlation between $\mathrm{d}-\mathrm{ROM}$ and the augmentation index (AI), which was acquired from waveforms between the carotid and femoral arteries, in both male and female subjects without traditional cardiovascular risk factors. However, the number of subjects enrolled in that study was relatively small $(n=169)$ and a multivariate analysis including d-ROM and $\mathrm{AI}$ was lacking ${ }^{26)}$.

Increased plasma serotonin concentrations and decreased endothelial function are characteristics of smokers compared with non-smokers ${ }^{10)}$. In a previous study, we reported that plasma serotonin concentrations and the ratio of serotonin in platelet-poor plasma (PPP) to whole blood (WB) were independently associated with d-ROM levels in non-smoking subjects ${ }^{28)}$. Under physiological conditions, serotonin works in 
Table 3b. Results of multivariate regression analysisa for factors possibly associated with the radial augmentation index adjusting for smoking duration and number of cigarettes smoked per day in all subjects, smokers, and non-smokers

\begin{tabular}{|c|c|c|c|}
\hline Variable & $\begin{array}{c}\text { Standardized } \\
\text { coefficient }\end{array}$ & $\begin{array}{l}\text { Standard } \\
\text { error }\end{array}$ & $p$-value \\
\hline \multicolumn{4}{|l|}{ All subjects } \\
\hline \multicolumn{4}{|l|}{ Non-interaction model } \\
\hline Age (years) & 0.37 & 0.064 & $<0.0001$ \\
\hline BMI $\left(\mathrm{kg} / \mathrm{m}^{2}\right)$ & -0.11 & 0.19 & $<0.05$ \\
\hline Systolic BP (mmHg) & 0.002 & 0.052 & 0.98 \\
\hline Diastolic BP (mmHg) & 0.14 & 0.075 & $<0.05$ \\
\hline Hemoglobin $(\mathrm{g} / \mathrm{dL})$ & 0.023 & 0.49 & 0.63 \\
\hline FPG $(\mathrm{mg} / \mathrm{dL})$ & -0.15 & 0.026 & $<0.001$ \\
\hline HDL-C (mg/dL) & -0.006 & 0.037 & 0.90 \\
\hline LDL-C (mg/dL) & -0.020 & 0.018 & 0.64 \\
\hline Triglycerides (mg/dL) & 0.090 & 0.009 & 0.054 \\
\hline eGFR $\left(\mathrm{mL} / \mathrm{min}\right.$ per $\left.1.73 \mathrm{~m}^{2}\right)$ & 0.11 & 0.041 & $<0.05$ \\
\hline d-ROM (Carratelli units) & 0.049 & 0.010 & 0.25 \\
\hline Cigarette smoking & 0.12 & 1.3 & $<0.05$ \\
\hline Smoking duration (years) & 0.080 & 0.052 & 0.17 \\
\hline Number of cigarettes smoked per day & 0.042 & 0.010 & 0.33 \\
\hline \multicolumn{4}{|l|}{ Interaction model } \\
\hline Product term of smoking and d-ROM & 0.87 & 0.018 & $<0.01$ \\
\hline Age (years) & 0.36 & 0.063 & $<0.0001$ \\
\hline BMI $\left(\mathrm{kg} / \mathrm{m}^{2}\right)$ & -0.10 & 0.19 & $<0.05$ \\
\hline Systolic BP (mmHg) & 0.010 & 0.051 & 0.87 \\
\hline Diastolic BP (mmHg) & 0.14 & 0.074 & $<0.05$ \\
\hline Hemoglobin $(\mathrm{g} / \mathrm{dL})$ & 0.030 & 0.49 & 0.52 \\
\hline $\mathrm{FPG}(\mathrm{mg} / \mathrm{dL})$ & -0.15 & 0.026 & $<0.001$ \\
\hline HDL-C (mg/dL) & -0.007 & 0.036 & 0.88 \\
\hline LDL-C (mg/dL) & -0.019 & 0.018 & 0.66 \\
\hline Triglycerides (mg/dL) & 0.093 & 0.009 & $<0.05$ \\
\hline eGFR $\left(\mathrm{mL} / \mathrm{min}\right.$ per $\left.1.73 \mathrm{~m}^{2}\right)$ & 0.11 & 0.041 & $<0.05$ \\
\hline d-ROM (Carratelli units) & -0.073 & 0.013 & 0.20 \\
\hline Cigarette smoking & -0.73 & 6.4 & $<0.01$ \\
\hline Smoking duration (years) & 0.074 & 0.051 & 0.20 \\
\hline Number of cigarettes smoked per day & 0.044 & 0.058 & 0.29 \\
\hline \multicolumn{4}{|l|}{ Smokers } \\
\hline Age (years) & 0.15 & 0.21 & 0.40 \\
\hline BMI $\left(\mathrm{kg} / \mathrm{m}^{2}\right)$ & -0.013 & 0.31 & 0.86 \\
\hline Systolic BP (mmHg) & 0.019 & 0.091 & 0.83 \\
\hline Diastolic BP (mmHg) & 0.096 & 0.12 & 0.27 \\
\hline $\mathrm{FPG}(\mathrm{mg} / \mathrm{dL})$ & -0.20 & 0.045 & $<0.01$ \\
\hline Hemoglobin $(\mathrm{g} / \mathrm{dL})$ & 0.080 & 0.84 & 0.27 \\
\hline $\mathrm{HDL}-\mathrm{C}(\mathrm{mg} / \mathrm{dL})$ & 0.033 & 0.069 & 0.65 \\
\hline LDL-C (mg/dL) & -0.056 & 0.029 & 0.45 \\
\hline Triglycerides $(\mathrm{mg} / \mathrm{dL})$ & 0.052 & 0.014 & 0.45 \\
\hline eGFR $\left(\mathrm{mL} / \mathrm{min}\right.$ per $\left.1.73 \mathrm{~m}^{2}\right)$ & 0.13 & 0.071 & 0.062 \\
\hline d-ROM (Carratelli units) & 0.17 & 0.015 & $<0.01$ \\
\hline Smoking duration (years) & 0.009 & 0.12 & 0.88 \\
\hline Number of cigarettes smoked per day & 0.20 & 0.28 & 0.11 \\
\hline
\end{tabular}


(Cont Table 3b)

\begin{tabular}{|c|c|c|c|}
\hline Variable & $\begin{array}{c}\text { Standardized } \\
\text { coefficient }\end{array}$ & $\begin{array}{l}\text { Standard } \\
\text { error }\end{array}$ & $p$-value \\
\hline \multicolumn{4}{|l|}{ Non-smokers } \\
\hline Age (years) & 0.41 & 0.044 & $<0.0001$ \\
\hline BMI $\left(\mathrm{kg} / \mathrm{m}^{2}\right)$ & -0.16 & 0.17 & $<0001$ \\
\hline Systolic BP (mmHg) & 0.016 & 0.044 & 0.77 \\
\hline Diastolic BP (mmHg) & 0.12 & 0.065 & $<0.05$ \\
\hline Hemoglobin $(\mathrm{g} / \mathrm{dL})$ & 0.031 & 0.45 & 0.47 \\
\hline FPG $(\mathrm{mg} / \mathrm{dL})$ & -0.088 & 0.025 & $<0.05$ \\
\hline HDL-C (mg/dL) & -0.043 & 0.032 & 0.33 \\
\hline LDL-C (mg/dL) & -0.064 & 0.017 & 0.12 \\
\hline Triglycerides $(\mathrm{mg} / \mathrm{dL})$ & 0.11 & 0.009 & $<0.05$ \\
\hline eGFR $\left(\mathrm{mL} / \mathrm{min}\right.$ per $\left.1.73 \mathrm{~m}^{2}\right)$ & 0.076 & 0.038 & 0.08 \\
\hline d-ROM (Carratelli units) & -0.060 & 0.008 & 0.13 \\
\hline
\end{tabular}

balance between endothelial cells and smooth muscle cells and modulates vascular tonus. Conversely, plasma serotonin released from activated platelets promotes thrombus formation and vasoconstriction under pathological conditions. These findings imply that oxidative stress caused by smoking promotes the release of serotonin, which may contribute to subsequent vascular inflammation and the development of atherosclerosis. In addition, in another study we proposed that the combination of the PPP:WB serotonin ratio, $\mathrm{d}-\mathrm{ROM}$, and C-reactive protein exhibited excellent diagnostic utility for coronary artery disease ${ }^{29)}$. However, measurement of the PPP:WB serotonin ratio and assessing vascular endothelial function are not easy and not practical for use in daily clinical practice $^{30)}$. The advantage of using the combination of $\mathrm{d}$-ROM levels and RAI is that both are simple and rapid to measure, even though oxidative stress and vascular function can be assessed using various different methods ${ }^{9,10,31 \text {. }}$.

Other risk factors, such as dyslipidemia and diabetes mellitus, did not contribute significantly to increased RAI in the present study. The reasons why RAI was inversely correlated with FPG and why RAI was not independently associated with diabetes mellitus are not clear. Furthermore, abnormal glucose metabolism (diabetes mellitus and impaired glucose tolerance) was not associated with RAI in the present study (data not shown). In line with our results, Eguchi et al. recently reported low RAI in patients with diabetes mellitus and speculated that proximal conduit-predominant arterial stiffness and reduced renal function may have resulted in decreased RAI in the diabetic subjects ${ }^{32}$.

Although the present study was designed to investigate the effects of oxidative stress on arterial stiffness in smokers and non-smokers, other important information may be obtained by analyzing the relationships among the RAI, d-ROM, and other factors in a future study focusing on factors other than smoking habit. Furthermore, it is important to determine whether smoking cessation influences oxidative stress and the RAI. An observational follow-up study that includes active smokers, non-smokers, and people who stopped smoking during the follow-up period is needed to address this issue.

The present study has several limitations and should be interpreted with caution. Specifically, the cross-sectional nature of the study and the relatively small number of subjects enrolled should be kept in mind. A selection bias cannot be completely excluded, because subjects in the present study were participants in a physical check-up program. Female subjects were not included in the present study because the number of female subjects eligible for inclusion was only half that of male subjects and the proportion of female smokers $(n=15)$ was extremely small. Moreover, the source of oxidative stress quantified by d-ROM was not identified and smoking-induced oxidative stress could not be evaluated directly. Biological assessments to demonstrate arterial response in vivo and to elucidate the mechanisms underlying the differences between smokers and non-smokers were not performed. Finally, important indices representing ath- 
A

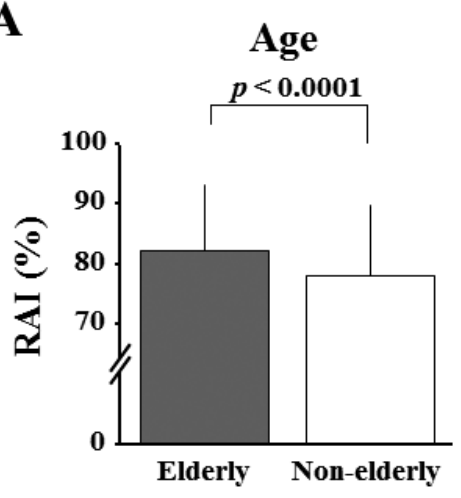

D

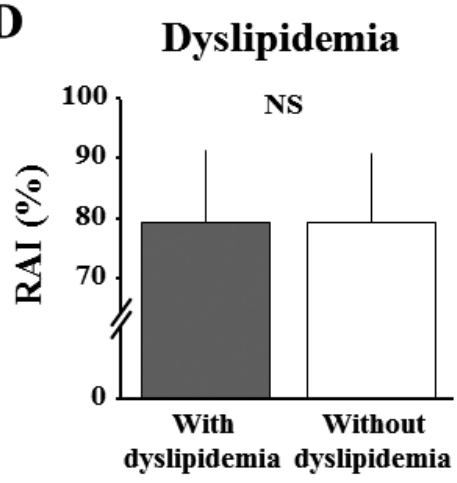

B

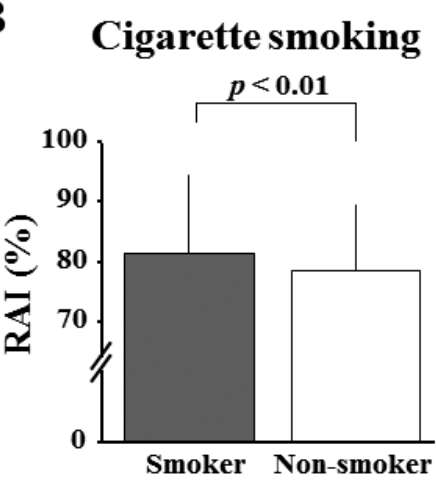

$\mathbf{E}$

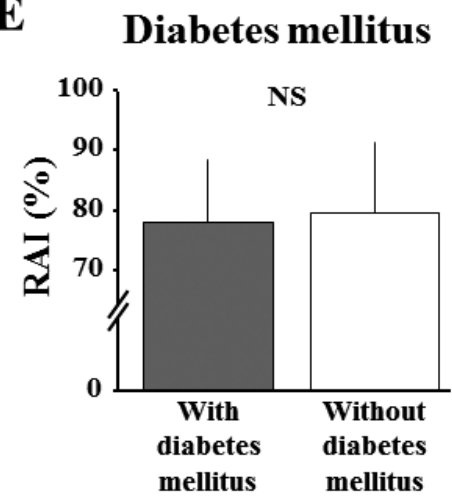

C

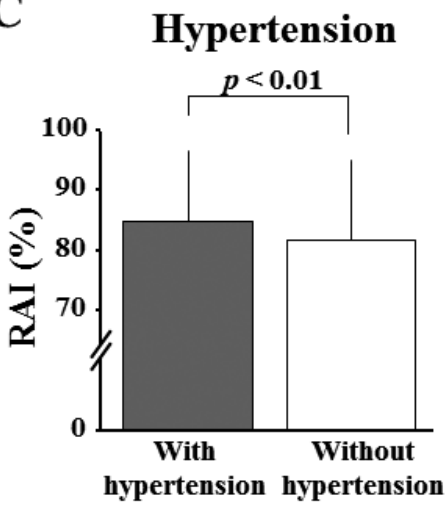

F

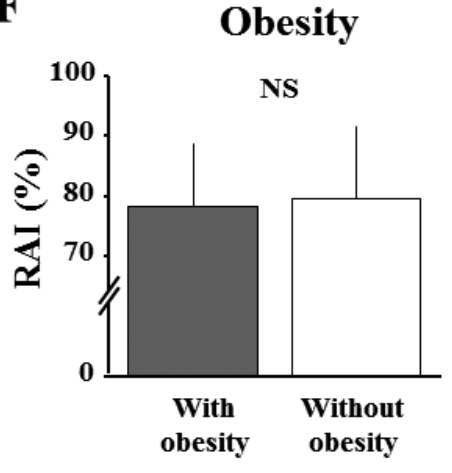

Fig. 2. Effects of different cardiovascular risk factors on the radial augmentation index (RAI).

Effects of (A) age (elderly being those aged > 65 years), (B) smoking, (C) hypertension, (D) dyslipidemia, (E) diabetes mellitus, and (F) obesity (where obesity is defined as a body mass index $>25 \mathrm{~kg} / \mathrm{m}^{2}$ ) on RAI. Data are the mean \pm SD.

Table 4. Results of logistic regression analysis for factors possibly associated with higher levels of the radial augmentation index in all subjects $(n=909)$

\begin{tabular}{lccc}
\hline \multicolumn{1}{c}{ Variables } & Category & OR $(95 \% \mathrm{CI})$ & $p$-value \\
\hline Elderly $(>65$ years old $)$ & Yes vs no & $1.91(1.37-2.66)$ & $<0.001$ \\
Cigarette smoking & Yes vs no & $1.74(1.27-2.43)$ & $<0.001$ \\
Hypertension & Yes vs no & $1.61(1.15-2.26)$ & $<0.01$ \\
Dyslipidemia & Yes vs no & $0.91(0.68-1.22)$ & 0.34 \\
Diabetes mellitus & Yes vs no & $0.72(0.44-1.20)$ & 0.21 \\
Obesity $\left(\mathrm{BMI}>25 \mathrm{~kg} / \mathrm{m}^{2}\right)$ & Yes vs no & $0.70(0.48-1.02)$ & 0.06 \\
\hline
\end{tabular}

The endpoint for the radial augmentation index was a value higher than the mean value $(79.4 \%)$.

$\mathrm{OR}$, odds ratio; CI, confidence interval; BMI, body mass index.

erosclerosis and arterial stiffness, such as the carotid intima-media thickness, pulse wave velocity, plaque score, and stiffness parameter $\beta$, were not measured in the present study, even though these indices are the gold standard for obtaining accurate information regarding subclinical atherosclerosis ${ }^{33-35)}$. Further research with a larger study population and using a prospective approach is needed to clarify the effects of oxidative stress on arterial stiffness in smokers and non-smokers.

\section{Conclusions}

Increased RAI is significantly associated with habitual smoking and, in smokers, with increased d-ROM levels. These results suggest that the effect of oxidative stress on arterial properties differs between smokers and non-smokers and that oxidative stress is 
closely associated with arterial stiffness, especially in smokers.

\section{Disclosure}

N. Ohte has received honoraria from DaiichiSankyo, Tanabe-Mitsubishi Pharma, Bayer Yakuhin, Astra-Zeneka, and Boehringer Ingelheim.

Department of Cardio-Renal Medicine, and Hypertension, Nagoya City University has received clinical research founding from Daiichi-Sankyo, Novartis Pharma, Otsuka Pharmaceutical, Astellas Pharma, Bayer Yakuhin, Actelion Pharma, MSD, and Takeda Pharmaceutical.

\section{References}

1) P.M. Vanhoutte, H. Shimokawa, E.H. Tang, M. Feletou, Endothelial dysfunction and vascular disease. Acta Physiol (Oxf), 2009; 196: 193-222

2) Ambrose JA, Barua RS. The pathophysiology of cigarette smoking and cardiovascular disease: an update. J Am Coll Cardiol, 2004; 43: 1731-1737

3) Zhang WZ, Venardos K, Chin-Dusting J, Kaye DM. Adverse effects of cigarette smoke on NO bioavailability: role of arginine metabolism and oxidative stress. Hypertension, 2006; 48: 278-285

4) Barua RS, Ambrose JA, Eales-Reynolds LJ, DeVoe MC, Zervas JG, Saha DC. Heavy and light cigarette smokers have similar dysfunction of endothelial vasoregulatory activity: an in vivo and in vitro correlation. J Am Coll Cardiol, 2002; 39: 1758-1763

5) Messner B, Bernhard D. Smoking and cardiovascular disease: mechanisms of endothelial dysfunction and early atherogenesis. Arterioscler Thromb Vasc Biol, 2014; 34: $509-515$

6) Erhardt L. Cigarette smoking: an undertreated risk factor for cardiovascular disease. Atherosclerosis, 2009; 205: 23-32

7) Sugiura T, Dohi $Y$, Takase H, Yamashita $S$, Tanaka $S$, Kimura G. Increased reactive oxygen metabolites is associated with cardiovascular risk factors and vascular endothelial damage in middle-aged Japanese subjects. Vasc Health Risk Manag, 2011; 7: 475-482

8) Higashi Y, Noma K, Yoshizumi M, Kihara Y. Oxidative stress and endothelial dysfunction: clinical evidence and therapeutic implications. Trends Cardiovasc Med, 2014; 24: $165-169$

9) Inoue N. Stress and atherosclerotic cardiovascular disease. J Atheroscler Thromb, 2014; 21: 391-401

10) Sjogren P, Basu S, Rosell M, Silveira A, de Faire U, Vessby B, Hamsten A, Hellenius ML, Fisher RM. Measures of oxidized low-density lipoprotein and oxidative stress are not related and not elevated in otherwise healthy men with the metabolic syndrome. Arterioscler Thromb Vasc Biol, 2005; 25: 2580-2586

11) Racké K, Schwörer H, Simson G. Nicotinic and muscarinic modulation of 5-hydroxytryptamine $(5-\mathrm{HT})$ release from porcine and canine small intestine. Clin Investig, 1992; 70: 190-200

12) Hirowatari $Y$, Hara K, Shimura $Y$, Takahashi H. Serotonin levels in platelet-poor plasma and whole blood from healthy subjects: relationship with lipid markers and coronary heart disease risk score. J Atheroscler Thromb, 2011; 18: 874-882

13) Vikenes K, Farstad M, Nordrehaug JE. Serotonin is associated with coronary artery disease and cardiac events. Circulation, 1999; 100: 483-489

14) Sugiura T, Dohi Y, Hirowatari Y, Yamashita S, Ohte N, Kimura G, Fujii S. Cigarette smoking induces vascular damage and persistent elevation of plasma serotonin unresponsive to 8 weeks of smoking cessation. Int J Cardiol, 2013; 166: 748-749

15) Shimamoto K, Ando K, Fujita T, Hasebe N, Higaki J, Horiuchi $M$, Imai $Y$, Imaizumi $T$, Ishimitsu $T$, Ito $M$, Ito $\mathrm{S}$, Itoh $\mathrm{H}$, Iwao $\mathrm{H}$, Kai $\mathrm{H}$, Kario $\mathrm{K}$, Kashihara $\mathrm{N}$, Kawano Y, Kim-Mitsuyama S, Kimura G, Kohara K, Komuro I, Kumagai H, Matsuura H, Miura K, Morishita R, Naruse M, Node K, Ohya Y, Rakugi H, Saito I, Saitoh S, Shimada K, Shimosawa T, Suzuki H, Tamura K, Tanahashi N, Tsuchihashi T, Uchiyama M, Ueda S, Umemura S; Japanese Society of Hypertension Committee for Guidelines for the Management of Hypertension. The Japanese Society of Hypertension Guidelines for the Management of Hypertension (JSH 2014). Hypertens Res, 2014; 37: 253-392

16) Teramoto T, Sasaki J, Ueshima H, Egusa G, Kinoshita M, Shimamoto K, Daida H, Biro S, Hirobe K, Funahashi T, Yokote K, Yokode M; Japan Atherosclerosis Society (JAS) Committee for Epidemiology and Clinical Management of Atherosclerosis. Diagnostic criteria for dyslipidemia. Executive summary of Japan Atherosclerosis Society (JAS) guideline for diagnosis and prevention of atherosclerotic cardiovascular diseases for Japanese. J Atheroscler Thromb, 2007; 14: 155-158

17) Committee of the Japan Diabetes Society on the Diagnostic Criteria of Diabetes Mellitus., Seino Y, Nanjo K, Tajima N, Kadowaki T, Kashiwagi A, Araki E, Ito C, Inagaki N, Iwamoto Y, Kasuga M, Hanafusa T, Haneda M, Ueki K. Report of the committee on the classification and diagnostic criteria of diabetes mellitus. J Diabetes Investig, 2010; 1: 212-228

18) Levey AS, Stevens LA, Schmid CH, Zhang YL, Castro AF 3rd, Feldman HI, Kusek JW, Eggers P, Van Lente F, Greene T, Coresh J; CKD-EPI (Chronic Kidney Disease Epidemiology Collaboration). A new equation to estimate glomerular filtration rate. Ann Intern Med, 2009; 150: 604-612

19) Takazawa K, Kobayashi H, Shindo N, Tanaka N, Yamashina A. Relationship between radial and central arterial pulse wave and evaluation of central aortic pressure using the radial arterial pulse wave. Hypertens Res, 2007; 30: 219-228

20) Tanaka S, Sugiura T, Yamashita S, Dohi Y, Kimura G, Ohte N. Differential response of central blood pressure to isometric and isotonic exercises. Sci Rep, 2014; 4: 5439

21) Qureshi G, Brown R, Salciccioli L, Qureshi M, Rizvi S, Farhan S, Lazar J. Relationship between aortic atherosclerosis and non-invasive measures of arterial stiffness. Ath- 
erosclerosis, 2007; 195: e190-e194

22) Rosenbaum D, Giral P, Chapman J, Rached FH, Kahn JF, Bruckert E, Girerd X. Radial augmentation index is a surrogate marker of atherosclerotic burden in a primary prevention cohort. Atherosclerosis, 2013; 231: 436-441

23) Blacher J, Safar ME. Large-artery stiffness, hypertension and cardiovascular risk in older patients. Nat Clin Pract Cardiovasc Med, 2005; 2: 450-455

24) Cereda CW, Tamisier R, Manconi M, Andreotti J, Frangi J, Pifferini V, Bassetti CL. Endothelial dysfunction and arterial stiffness in ischemic stroke: the role of sleep-disordered breathing. Stroke, 2013; 44: 1175-1178

25) Fitch RM, Vergona R, Sullivan ME, Wang YX. Nitric oxide synthase inhibition increases aortic stiffness measured by pulse wave velocity in rats. Cardiovasc Res, 2001; 51: 351-358

26) Patel RS, Al Mheid I, Morris AA, Ahmed Y, Kavtaradze N, Ali S, Dabhadkar K, Brigham K, Hooper WC, Alexander RW, Jones DP, Quyyumi AA. Oxidative stress is associated with impaired arterial elasticity. Atherosclerosis, 2011; 218: 90-95

27) Csordas A, Wick G, Laufer G, Bernhard D. An Evaluation of the Clinical Evidence on the Role of Inflammation and Oxidative Stress in Smoking-Mediated Cardiovascular Disease. Biomark Insights, 2008; 3: 127-139

28) Kato T, Umeda A, Miyagawa K, Takeda H, Adachi T, Toyoda S, Taguchi I, Inoue T, Node K. Vareniclineassisted smoking cessation decreases oxidative stress and restores endothelial function. Hypertens Res, 2014; 37: 655-658

29) Sugiura T, Dohi Y, Yamashita S, Hirowatari Y, Fujii S, Ohte N. Serotonin in peripheral blood reflects oxidative stress and plays a crucial role in atherosclerosis: Novel insights toward holistic anti-atherothrombotic strategy. Atherosclerosis, 2016; 246: 157-160

30) Hirowatari Y, Hara K, Kamihata H, Iwasaka T, Takahashi H. High-performance liquid chromatographic method with column-switching and post-column reaction for determination of serotonin levels in platelet-poor plasma. Clin Biochem, 2004; 37: 191-197

31) Schnabel RB, Schulz A, Wild PS, Sinning CR, Wilde S, Eleftheriadis M, Herkenhoff S, Zeller T, Lubos E, Lackner KJ, Warnholtz A, Gori T, Blankenberg S, Münzel T. Noninvasive vascular function measurement in the community: cross-sectional relations and comparison of methods. Circ Cardiovasc Imaging, 2011; 4: 371-380

32) Eguchi K, Hoshide S, Miyashita H, Nagasaka S, Kario K. Why the radial augmentation index is low in patients with diabetes: The J-HOP study. Atherosclerosis, 2016; 246: 338-343

33) Takahara M, Katakami N, Osonoi T, Saitou M, Sakamoto F, Matsuoka TA, Shimomura I. Different Impacts of Cardiovascular Risk Factors on Arterial Stiffness versus Arterial Wall Thickness in Japanese Patients with Type 2 Diabetes Mellitus. J Atheroscler Thromb, 2015; 22: 971-980

34) Tomiyama H. Arterial Stiffness: Is This a Marker for the Current Status or Future? J Atheroscler Thromb, 2016; 23: 1026-1027

35) Saiki A, Sato Y, Watanabe R, Watanabe Y, Imamura H, Yamaguchi T, Ban N, Kawana H, Nagumo A, Nagayama D, Ohira M, Endo K, Tatsuno I. The Role of a Novel Arterial Stiffness Parameter, Cardio-Ankle Vascular Index (CAVI), as a Surrogate Marker for Cardiovascular Diseases. J Atheroscler Thromb, 2016; 23: 155-168 